\title{
Level of Serum Trace Element in Preoperative and Postoperative Period of Symptomatic Hydatid Disease Patients
}

\author{
AK SHARMA ${ }^{\mathrm{a}}$, SK SHARMA ${ }^{\mathrm{b}}$
}

\section{Summary:}

Introduction: Hydatid disease is most prevalent parasitic zoonosis in tropical countries causing serious problem to public health and national economy. Very few studies have published regarding alteration of serum trace element in hydatid disease.

Aims \& Objective: The aim of the study is to demonstrate the relationship between the serum zinc, magnesium and copper level in patients of hydatid disease, their alteration after surgery and demographic profile of the patients.

Method: To evaluate the level of serum zinc, magnesium and copper in pre and postoperatively in patient with hydatid disease along with their demographic characteristics. This study was carried out on the patients with hydatosis in the department of surgery in Govt. Medical College, Kota.

\section{Introduction:}

Hydatid disease is a parasitic infection caused by larval stage of Echinococcus granulosus in human. The most frequently involved organ is the liver $(65 \%)$, other organs involved are the lungs (25\%) and, less frequently, the spleen, kidneys, heart, bone and central nervous system and head and neck region ${ }^{1,2,3}$. The disease is endemic in central India ${ }^{4}$ The relationship of trace elements in certain disease group such as cancer ,rheumatoid arthritis have been well identified. 5,6 However there are only very few studies published in literature showing the relationship between serum trace elements and hydatid disease. The exact mechanism by which the level of serum trace elements alters in infectious and inflammatory disease is clearly not known ${ }^{7,8}$. It has been reported that it could be due to the acute phase reaction by host response against inflammation. ${ }^{9}$ The aim of the study is to demonstrate the relationship between the serum zinc, magnesium and

a. Dr. Atul K. Sharma, Dept. of Surgery, Kota, India.

b. Dr. Santosh K. Sharma, Dept. of Surgery, Kota, India.

Address of Correspondence: Dr. Atul K. Sharma, Dept. of Surgery, Kota, India.

Received: 15 February, 2012

Accepted: 5 September, 2012
Serum levels of serum zinc, magnesium and copper were compared preoperatively and six months after surgery in 61 patients (23 male and 38 female) with hydatid cyst liver, lung and other sites.

Result: Mean serum level of zinc and magnesium were increased postoperatively while serum copper levels were decreased significantly $(p<0.0001)$. Hydatid disease is more common in females and the most common organ involved is liver followed by lung and other sites.

Conclusion: Estimation of serum trace elements in post operative patients of hydatid disease can be used as a diagnostic tool for recurrence along with relevant radiological and serological investigation.

Key Words: Hydatid disease, serum trace elements.

(J Bangladesh Coll Phys Surg 2012; 30: 201-204)

copper level in patients of hydatid disease, their alteration after surgery and demographic profile of the patients.

Material and Method:

Patients with hepatic and extra hepatic hydatosis [61 patients,(23 males, 38 females)] who were treated from June 2009 to July 2011 at Department of General surgery M.B.S. hospital Kota were included in the study. Patients who could not be monitored post operatively were excluded from the study. A written informed consent was taken from the patient and relatives and institutional ethical clearance was also sought. Preoperative diagnosis was determined by clinical examination, radiological imaging (Ultrasound and Computed tomography) and serology. Anti Echinococcus antibodies were determined by Echinococcosis western blotting. Thorough history regarding symptom and their duration were taken after recording demographic data. Size of the cyst, its localization was also noted. Total cystectomy was done in all cases of hepatic hydatid cysts and abdominal drain was put in cyst cavity in all cases as safeguard for biliary fistula. Pulmonary hydatid cysts were managed by posterolateral thoracotomy and 
cystostomy. Other sites hydatid cysts were managed by excision of cyst and diagnosed postoperatively by histopathological examination. Monitoring period for all patients was of six months. Serum Zinc (Zn), Magnesium $(\mathrm{Mg})$ and Copper $(\mathrm{Cu})$ levels were measured in all the patients preoperatively and six months after treatment. Neither specific diet nor any medications that alter serum trace element was advised to patients. Serum samples were collected early morning to avoid day time dehydration giving false levels. Albendazole was given to all the patients in dose of 10 $\mathrm{mg} / \mathrm{kg} /$ day for six months with 3 weeks with and 1 week without medication. No specific side effects were observed in six months. Patients were thoroughly evaluated by both radiology (USG and CT abdomen) and serologically. Anti echinococcal antibodies were found to be positive nearly all patients six months after surgery.

Total 65 patients were operated in the spawn of two years. Two patients who did not come for follow up and two patients took multi vitamin, multi mineral drug supplementation for other cause were excluded from the study.

For estimation for serum $\mathrm{Zn}, \mathrm{Mg}$ and $\mathrm{Cu} 5 \mathrm{ml}$ of venous blood was collected into a metal free plain plastic vials. Sample were left standing at room temperature for $30 \mathrm{~min}$ and then serum was separated by centrifuging at $3000 \mathrm{rpm}$ for $15 \mathrm{~min}$. and preserved at $-20{ }^{\circ} \mathrm{C}$. Serum $\mathrm{Zn}, \mathrm{Mg}$, and $\mathrm{Cu}$ were measured with the help of atomic absorption spectrophotometer (AAS 4141A). AAS is a PC based instrument for absorption and emission analysis and used for quantitative element analysis by measuring the absorbance of a sample atomized in a flame. The data processing and partial control of the instrument are done by P.C.

Serum $\mathrm{Zn}, \mathrm{Mg}$ and $\mathrm{Cu}$ estimation was done by AAS. Serum was diluted with deionized water in the ratio of 1:1, 1:5 1:50 for estimation of serum copper, zinc and magnesium to avoid possibility of clogging of micro tubes in AAS. Values were recorded for $\mathrm{Zn}, \mathrm{Mg}$ and $\mathrm{Cu}$ at wavelength of 213.9 and $285.2,324.8 \mathrm{~nm}^{10,11}$.

Stastical analysis was performed by SPSS version 12 . Comparison for each variable was performed by using student t-test and Pearson correlation test. Data were expressed in terms of mean \pm S.D., number and $\mathrm{p}$ value $<0.0001$ is considered significant.

\section{Result:}

Patient's characteristics with demographic profile is demonstrated in table no.(1).Hydatid disease has female preponderance with $1.65: 1$ ratio with mean age of presentation $34.14 \pm 15.06$ years ( $34.52 \pm 18.2$ in male and $33.76 \pm 13.46$ in females) as shown in table no.(1). Hydatid cysts were more commonly located in right lobe of liver than left (70\% right lobe and $22.5 \%$ left lobe). Cysts were also found in lungs and other sites like parotid, Submandibular gland, breast and intraperitoneal in pelvis. Mean duration of symptoms was $11.7 \pm 6.8$ months. Serum trace elements $\mathrm{Zn}, \mathrm{Mg}$ and $\mathrm{Cu}$ were compared in patients' pre and postoperatively. Serum zinc levels were increased in postoperative patients $(85.50 \pm 2.23 \mu \mathrm{g} / \mathrm{dl})$ than preoperative patients $(63.40$ $\pm 9.12 \mu \mathrm{g} / \mathrm{dl})$ significantly $(\mathrm{P}<0.0001)$. Serum levels of magnesium were also increased significantly $(\mathrm{P}<0.0001)$ in operated patients of hydatid disease $(22.92 \pm 2.92 \mathrm{mg} / \mathrm{l})$ than preoperative patients $(14.16 \pm$ $2.59 \mathrm{mg} / \mathrm{l})$.Serum copper levels were decreased significantly $(\mathrm{P}<0.0001)$ in postoperative patients than preoperative patients $(99.34 \pm 1.95 \mu \mathrm{g} / \mathrm{dl} \mathrm{v} / \mathrm{s} 135.50 \pm$ $8.67 \mu \mathrm{g} / \mathrm{dl})$.

\section{Table-I}

\section{Patient's characteristics}

\begin{tabular}{|c|c|c|}
\hline \multirow[t]{3}{*}{1} & Gender & No. of patients \\
\hline & Male & 23 \\
\hline & Female & 38 \\
\hline \multirow[t]{3}{*}{2} & Age (Years; Mean \pm S.D.) & $34.14 \pm 15.06$ \\
\hline & Male & $34.52 \pm 18.2$ \\
\hline & Female & $33.76 \pm 13.46$ \\
\hline \multirow[t]{3}{*}{3} & Socioeconomic Class & \\
\hline & Lower & $49(80.3 \%)$ \\
\hline & Upper & $12(19.7 \%)$ \\
\hline 4 & $\begin{array}{l}\text { Contact with animal/pet } \\
\text { present in: }\end{array}$ & $92 \%$ \\
\hline \multirow[t]{8}{*}{5} & Cyst localization (percent) & \\
\hline & Liver- & $65.57 \%$ \\
\hline & a) Right Lobe & $70 \%$ (Of hepatic hydatid) \\
\hline & b) Left Lobe & $22.5 \%$ (Of hepatic hydatid) \\
\hline & c) Both Lobe & $7.5 \%$ (Of hepatic hydatid) \\
\hline & Lung & $11.47 \%$ \\
\hline & Both Liver and Lung & $9.83 \%$ \\
\hline & Others & $13.11 \%$ \\
\hline 4 & Duration of symptoms & $11.7 \pm 6.8$ months \\
\hline
\end{tabular}

\section{Discussion:}

In this study the mean serum level of trace elements zinc, magnesium and copper were compared pre and 
postoperatively. The serum levels of zinc and magnesium were significantly increased ( $P$ value $<0.0001)$. The levels of copper were decreased significantly ( $\mathrm{P}$ value $<0.0001$ ). The correlation of serum trace elements levels in various diseases like rheumatoid arthritis, cancer, immunodefiency diseases and their probable role in pathogenesis were studied. There were only few studies published in literature to best of our knowledge regarding comparison of serum trace elements level in patients of hydatid disease in pre and post operative period. Ozen et al in a study which included 12 patients and 12 sheeps with cystic Echinococcosis concluded decreased levels of serum selenium and zinc and increased levels of serum copper in patients than normal healthy indivisuals ${ }^{8}$.

Hydatid disease is a parasitosis known as hydatidosis or Echinococcosis caused by the larval stage of the cestode tapeworm E. granulosus or E.multilocularis. Human beings are the incidental intermediate host. Hydatid cyst is rare in the head and neck area. Only few cases are reported in the literature 9,12 . We have one case of hydatid cyst parotid and one case of hydatid thyroid in our study. In our cases series, diagnosis was based mainly on imaging and HPE; only in few cases biologic or serologic tests were also performed. Discrepancies between radiological imaging and serological diagnosis are best resolved by cytology of the drained fluid and or Histopathological examination of the excised cyst ${ }^{13}$. Surgery, conservative or radical, is still the treatment of choice for all locations of the disease. Until now it has not been clearly stated in the literature if there are benefits to minimal surgery compared to radical surgical treatment ${ }^{14}$.

This study showed significant evidence of a rise in mean serum zinc and serum magnesium with a decrease in serum copper in sera of patients with hydatid disease postoperatively.

The major function of copper metalloproteinase includes oxidative-reduction reaction. Copper is an integral component of enzyme like ceruloplasmin, cytochrome c oxidase, super oxide dismutase and lysyl oxidase and tyrosinase. Many pathological conditions have been attributed to the loss of cuproenzyme activity. It has been reported that in protein calorie malnutrition, serum $\mathrm{Cu}$ levels can be used as indicator of severity of malnutrition ${ }^{15}$. In our study mean serum copper concentration was decreased significantly postoperatively which was also supported by the previous studies ${ }^{8}$. This finding showed a negative effect of hydatosis on hepatic copper concentration, that is a major site for copper reserving. Due to this hydatosis could increase the serum copper concentration via liver copper depletion and may interfere determining the normal blood copper level. On the other hand gravid cyst may need more copper for their growth.

The metabolic functions of zinc are based largely on its presence as an essential component of many metalloenzymes involved in virtually all aspects of metabolism. Zinc is an integral component of nearly 300 enzymes. Important zinc containing metalloenzymes in human include carbonic anhydrase, alkaline phosphatase, RNA and DNA polymerase, thymidine kinase, carboxypeptidase and alcohol dehydrogenase. In a work many chemical compounds including organic, protein, enzymes have been encountered in the hydatid cyst fluid ${ }^{16}$. This indicates that

these hydatid cysts need these components for the metabolic processes which are required for their growth and survival. Zinc also stabilizes the structure of protein and nucleic acids, preserves the integrity of subcellular organelles, participates in transport process and has an important role in the immune system ${ }^{8}$. Immunoglobulin $A$ and $G$ have been recovered in the hydatid fluid. In addition, it is well known those hydatid fluid and cyst walls are a good source of antigen which can be used in sero-diagnosis of hydatid disease ${ }^{17}$.

Magnesium though considered as trace element, it is the fourth most abundant cation in the body and only second to potassium intracellularly. Deficiency of magnesium mainly leads to impairment of neuromuscular functioning, tetany, convulsion and electrocardiographic changes. Chronic alcoholism, malnourishment and impairment of renal function lead to hypomagnesaemia. Sakman et al ${ }^{18}$ in their study concluded that there is a positive correlation in symptom duration and fertility of cyst. These finding of the study are probably explained by consumption of magnesium and zinc by the parasite and secretion of copper into circulation by parasite.

As far as follow up of patient is considered no investigation alone can definitely determine the 
recurrence as cyst like structures are can be seen on imaging till one year and serological tests are also positive for first six months. So we recommend estimation of serum trace elements levels postoperatively along with radiological and serological investigation. Long term studies on large number of patient including recurrent cases with long term follow up studies are required.

In conclusion in our study levels of serum $\mathrm{Zn}$ and $\mathrm{Mg}$ were increased postoperatively significantly and serum $\mathrm{Cu}$ were decreased significantly. This can be explained by secretion of $\mathrm{Cu}$ in serum and consumption of $\mathrm{Zn}$ and $\mathrm{Mg}$ by parasite (Echinococcus) in addition to acute phase reaction. We recommend estimation of serum trace elements levels in postoperative follow up to determine recurrence along with radiological and serology.

\section{References:}

1. Celik A, Turanli M, Kutun S, Delibasi T, Mengi N, Comert $\mathrm{E}$ et al. Unusual location of hydatid cyst: soft tissue mass in the neck. European arch Otorhinolaryngol. 2006;263: 1147-1150.

2. Tekin M, Osma U, Yaldiz M, Topcu I. Preauricular hydatid cyst: an unusual location for echinoccosis. Eur Arch Otorhinolaryngol 2004;261:87-89.

3. Amr SS, Amr ZS, Jitawi S, Annab H. Hydatidosis in Jordan: an epidemiological study of 306 cases. Ann Trop Med Parasitol 1994; 88:623-7.

4. Taori KB, Mahajan SM, Hirawe SR, Mundhada RG. Hydatid disease of breast. Indian J Radiology Imaging. 2004; 14:57-60

5. Riviera MT, Desouza AP, Araujo-Jorge TC, De castro SL, Vandepras J. Trace element, innate immune response and parasites. Clin. Chem. Lab Med.2003;41:1020-1025.

6. Jain A, Mukherjee A, Chattopadhyay D,Saha K. Biometals in skin and sera of leprosy patients and their correlation to trace element content of M. Leprae and histological type of disease; a comparative study with cutaneous tuberculosis. Int J Lepr other Mycobact dis. 1995; 63:249-258.

7. Kassu A, Yabutani T, Mahmud ZH, Mohammad A, Nguyen $\mathrm{N}$, Huong BT et al. Alterations in serum levels of trace elements in tuberculosis and HIV infections. Eur J Clin Nutr. 2006;60: 580-586.

8. Ozen N, Celik C, Ozkan K, Malazgirt Z, Isimer A, Sayal A. Trace elements in hydatid disease. J Trace Elem Electrolytes Health Dis. 1992; 6:67-70.

9. Darabi M, Varedi P, Mohebi AR, Mahmoodi S, Varedi P, Nabavizadeh SA et al. Hydatid cyst of the parotid gland. Oral maxillofac. Surg. 2009;13:33-35.

10. Butrimovitz GP,Purdy WC. The determination zinc in blood plasma by atomic absorption spectrometry. Anal chim acta 1977; 94:63-73.

11. Fernandej FJ, Kahn HL. Clinical method for atomic absorption spectrometer. Clin chem. Newsl.1971; 3:24-26.

12. Rajendra Gopal SV, Mahadeva Sastry N, Venkataramana G. Hydatid cyst of parotid. A case report. Indian J Pathol Microbiol. 1985; 28:75-76.

13. Hira PR, Behbehani K, Shweiki H, Abu-Nema T, Soni CR. Hydatid liver disease: problems in diagnosis in the Middle East endemic area. Ann Trop Med Parasitol 1988; 82: 357-361.

14. Dziri C, Haouet K, Fingerhut A. Treatment of hydatid cyst of the liver: where is the evidence? World J. Surg. 2004; 28:731-736.

15. Squali Houssaïni FZ, Iraqi MR, Arnaud J, Richard MJ, Favier A. Trace elements and protein calorie malnutrition in $\mathrm{FeS}$ area (Morocco). Biomed Pharmacather1997; 51:349-351.

16. French CM, Ingera EW. Hydatid disease in the Turkana District of Kenya. V. Problems of interpretation of data from a mass serological survey. Ann Trop Med Parasitol 1984; 78: 213-8.

17. Sakman G, Parasak CK, Koltas IS, Seydaoglu G, Sonmez H, Hanta I. Evaluating of the trace elements in preoperative and postoperative duration of hydatid surgery. Saudi Med J 2008; 29: 69-74. 